\title{
Relationship between Moisture Behavior and Gaseous Volatile Organic Compounds Removal in a Biofiltration System
}

\author{
Ahmad Masoud Mansoori ${ }^{1}$, Miyuki Mori ${ }^{1}$ and Takashi Higuchi ${ }^{2}$ \\ 1. Graduate School of Science and Engineering, Ritsumeikan University, 1-1-1 Noji-higashi, Kusatsu, Shiga 525-8577, Japan \\ 2. School of Science and Engineering, Ritsumeikan University, 1-1-1 Noji-higashi, Kusatsu, Shiga 525-8577, Japan
}

\begin{abstract}
Studies on the relationship between moisture behavior and gaseous VOCs (Volatile Organic Compounds) removal efficiency of packed tower biofilters are limited. In this research, the nutrient holding capacity, moisture evaporation rate and gaseous toluene and MEK (Methyl Ethyl Ketone) removal efficiencies of bioreactors with porous synthetic resin as the packing material were simultaneously observed. The nutrient holding capacity in one of the reactors was higher than those of the other two because its packing layer was frequently supplied with a nutrient solution by soaking. This reactor exhibited the highest toluene removal efficiency. However, excessive biomass growth was observed in this reactor. The reactor with a less frequent supply of nutrient solution by soaking showed a slightly lower toluene removal efficiency, possibly due to lack of nutrients in the packing layer. The reactor that was fed with the nutrient solution by spraying it onto the packing layer (a common method for supplying moisture) had the lowest toluene removal efficiency, mainly because of the uneven distribution of nutrients. Moreover, the moisture evaporation rate in the packing layer during moisture supply and heat balance were determined.
\end{abstract}

Key words: Biofiltration, gaseous VOCs, moisture supply, heat balance.

\section{Introduction}

Biofiltration, which is a biological technology for air pollution control, has emerged as an off-gas treatment method over the past several decades. It is regarded as a more environmental friendly and economical method than conventional physical/chemical treatment techniques $[1,2]$. To sustain the high removal efficiency of biofilters, parameters such as water content, inlet air relative humidity, temperature, $\mathrm{pH}$ and nutrient concentrations should be controlled [3].

The microbial activity in biofilters is highly dependent on the moisture content of the filter bed. Therefore, maintaining an appropriate moisture content of the packing material is essential for its effectiveness [4]. Controlling the moisture content of the bed material is a critical aspect of biofilter operation [5].

Corresponding author: Takashi Higuchi, professor, main research field: air pollution/malodor control.
Lack of moisture dries out the filter bed and air flows through the cracks/fissures developed [6]. The packing material may suffer other types of irreversible damage by drying [7]. Moreover, insufficient moisture in the packing bed results in low growth of microorganisms, thereby reducing filter performance [8].

When excess water is present in the filter bed, anaerobic zones may form and the filter bed may be compacted and clogged, which restricts the transport of oxygen and hydrophobic VOCs to the biofilm, thereby limiting the reaction rate [9].

The optimal water contents of different packing materials differ depending on the surface area, porosity and other factors. The moisture content should be within 30-60\% by weight for optimal biofiltration [6]. Generally, the recommended water content is $50 \%$ of the water-holding capacity of the material [10]. Controlling the moisture content in biofilters requires a 
better understanding of how the packing material dries out due to changes in inlet air temperature, relative humidity and metabolic heat generated during pollutant oxidation.

Some researchers have proposed novel designs of biofiltration systems, for example, a new type of system called the SFMC (Switch-Feed Multi-Column) biofilter was developed [11]. The main characteristic of the SFMC is that the gas flow direction can be changed to allow microorganisms to grow evenly in the filter bed. Another unique characteristic is that the filter bed is soaked with nutrient solution through irrigation to ensure uniform distribution of water and nutrients throughout the filter bed.

In this study, the moisture and nutrient holding capacities of the packing material of the biofiltration system were continuously observed. Furthermore, the removal of gaseous toluene and MEK (Methyl Ethyl Ketone) were simultaneously monitored. Based on these results the relationship between the moisture behavior and the removal of target gases was analyzed. The water and heat balances were analyzed and their influences on the removal of target gases were considered. Each reactor in the experiment was irrigated either by soaking or spraying, and the observed results were compared.

\section{Materials and Methods}

\subsection{Experimental Setup}

In this experiment, air contaminated with VOCs was treated by three reactors (packed-column type biofilters). The diameter and packing height of the reactors were $0.1 \mathrm{~m}$ and $0.3 \mathrm{~m}$, respectively. Gaseous VOCs generated from a toluene-MEK liquid mixture using a VOC gas generator were diluted with indoor air and flowed into the reactors. Two of the reactors were supplied with nutrient solution (i.e., irrigation) by soaking according to the method used in the SFMC. The other reactor was irrigated by spraying, which is a generally used method in biofiltration. The schematic diagram of the experimental setup is shown in Fig. 1.
P: Air pump 1. Flow meter 2. VOC generator

3. Nutrient solution tank (measuring cylinder)

4. Switching valve (closed during soaking)

5. Packed tower 6. Gas sampling port BF1-BF3: bioreactors (filter layer)

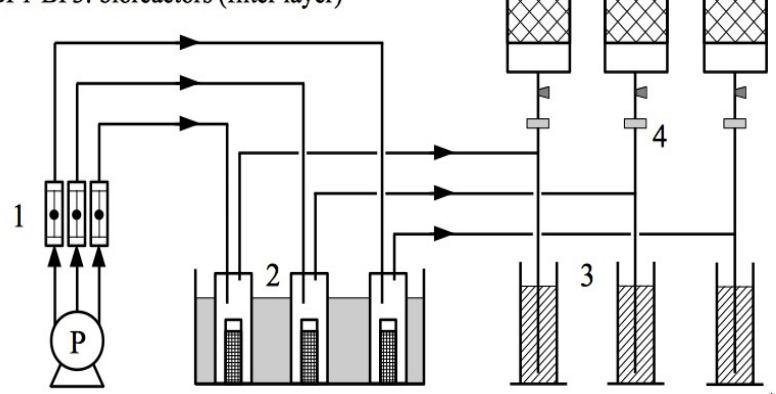

Fig. 1 Experimental setup for bioreactors.

\subsection{Packing Material}

The porous packing material used in the reactors for these experiments was PVF (Polyvinyl Formal) resin (Be-Fine LL prototype, AION Co., Ltd.). Fig. 2 shows the structure and physical properties of this packing material.

\subsection{Operating Conditions}

In the experiments, each of the three reactors (BF1, $\mathrm{BF} 2$ and BF3) was operated under unique irrigation conditions. The operating conditions of the reactors and the composition of the nutrient solution used for irrigation are shown in Table 1 and Table 2, respectively. All the reactors were allowed to acclimatize for 10 days to the irrigation frequency of twice weekly. In both the irrigation methods, soaking and spraying, the same volume $(1,100 \mathrm{~mL})$ of nutrient solution was poured on top of the filter bed using a commercially available watering pot. The duration of an irrigation

\begin{tabular}{cccc}
\hline $\begin{array}{l}\text { Average pore } \\
\text { diameter }(\mu \mathrm{m})\end{array}$ & $\begin{array}{l}\text { Compressive } \\
\text { strength at 20\% } \\
\text { contraction }(\mathrm{kPa})\end{array}$ & $\begin{array}{l}\text { Void ratio } \\
(\%)\end{array}$ & $\begin{array}{l}\text { Water retention } \\
\text { ratio }(\%)\end{array}$ \\
\hline 2000 & 60 & 96 & 1500 \\
\hline $\begin{array}{l}\text { Dimension } \\
\text { of one piece } \\
\text { (Unit ; } \mathrm{mm})\end{array}$ & Photo
\end{tabular}

Fig. 2 Specification of the packing material. 
Table 1 Operating conditions of the bioreactors.

\begin{tabular}{|c|c|c|c|c|}
\hline & & $\mathrm{BF} 1$ & $\mathrm{BF} 2$ & BF3 \\
\hline Time/period & (d) & $1-46$ & $1-46$ & $1-46$ \\
\hline Irrigation method & & soaking & soaking & spraying \\
\hline Frequency of irrigation & (times/week) & 2 & 1 & 2 \\
\hline $\begin{array}{l}\text { Average inlet gas } \\
\text { temperature }\end{array}$ & $\left({ }^{\circ} \mathrm{C}\right)$ & 21.0 & 20.7 & 20.7 \\
\hline Flow rate & $\left(\mathrm{L} \cdot \mathrm{min}^{-1}\right)$ & 5 & 5 & 5 \\
\hline Residence time & $(\mathrm{sec})$ & 28.8 & 28.8 & 28.8 \\
\hline $\begin{array}{l}\text { Average inlet toluene } \\
\text { concentration }\end{array}$ & (ppm) & 38.8 & 42.8 & 44.0 \\
\hline $\begin{array}{l}\text { Average inlet MEK } \\
\text { concentration }\end{array}$ & (ppm) & 57.4 & 55.8 & 67.2 \\
\hline $\begin{array}{l}\text { Average inlet load of } \\
\text { toluene }\end{array}$ & $\left(\mathrm{g} \cdot \mathrm{m}^{-3} \cdot \mathrm{h}^{-1}\right)$ & 16.5 & 20.5 & 19.2 \\
\hline $\begin{array}{l}\text { Average inlet load of } \\
\text { MEK }\end{array}$ & $\left(\mathrm{g} \cdot \mathrm{m}^{-3} \cdot \mathrm{h}^{-1}\right)$ & 20.5 & 20.9 & 25.8 \\
\hline
\end{tabular}

Table 2 Composition of the nutrient solution used for irrigation.

\begin{tabular}{ll}
\hline Nutrient components & Concentration $\left(\mathrm{mg} \cdot \mathrm{L}^{-1}\right)$ \\
\hline $\mathrm{KNO}_{3}$ & 4,000 \\
$\mathrm{NH}_{4} \mathrm{Cl}$ & 2,100 \\
$\mathrm{Na}_{2} \mathrm{HPO}_{4} \cdot 12 \mathrm{H}_{2} \mathrm{O}$ & 7,200 \\
$\mathrm{KH}_{2} \mathrm{PO}_{4}$ & 2,700 \\
$\mathrm{MgSO}_{4} \cdot 7 \mathrm{H}_{2} \mathrm{O}$ & 2,100 \\
$\mathrm{CaCl}_{2} \cdot 2 \mathrm{H}_{2} \mathrm{O}$ & 170 \\
$\mathrm{ZnSO}_{4} \cdot 7 \mathrm{H}_{2} \mathrm{O}$ & 8 \\
$\mathrm{Na}_{2} \mathrm{Mo}_{4} \cdot 2 \mathrm{H}_{2} \mathrm{O}$ & 43 \\
$\mathrm{CoCl}_{2} \cdot 6 \mathrm{H}_{2} \mathrm{O}$ & 65 \\
$\mathrm{MnCl}_{2} \cdot 4 \mathrm{H}_{2} \mathrm{O}$ & 670 \\
$\mathrm{FeSO}_{4} \cdot 7 \mathrm{H}_{2} \mathrm{O}$ & 73 \\
\hline
\end{tabular}

process (both soaking and spraying) was 5 min for each reactor. The drainage was collected in a $3-\mathrm{L}$ measuring cylinder to measure the volume of liquid and re-used for irrigation. Fresh nutrient solution was prepared and added to the drainage to make up for the volume lost.

\subsection{Measurement Methods}

The gas samples containing a mixture of toluene and MEK were collected from the sampling ports provided in at the inlet and outlet of each reactor with a $1.0 \mathrm{~mL}$ syringe (Ito micro syringe, Ito Seisakusho Co., Ltd., Japan). Samples were collected both before and after irrigation. Sampling after irrigation was conducted 15 minutes after the irrigation.
Toluene and MEK in the gas samples were measured using a gas chromatograph (GC-2014, Shimadzu, Japan) equipped with an FID (Flame Ionized Detector) detector and a wide-bore capillary column (G-300, Chemicals Evaluation and Research Institute, Japan) commonly used for VOCs measurement. Helium was used as the carrier gas at a flow rate of $20 \mathrm{~mL} \cdot \mathrm{min}^{-1}$ and the column temperature was set at $50{ }^{\circ} \mathrm{C}$.

Temperature and humidity of the inlet and outlet airflow of the reactors were measured at the same sampling ports used for gas sample collection using a thermo-recorder (Thermo Recorder RS-12, Espec Mic Corp., Japan). These measurements were recorded once daily. However, like gas sample collection, these measurements were recorded both before and after the irrigation on days when irrigation was carried out. To acquire stable results, the values read by the thermo-recorder $5 \mathrm{~min}$ after insertion of the recorder's sensor were considered. Humidity measurement was carried out simultaneously once a week using a gas tube detector (No.177SA, Komyo Rikagaku Kogyo Corp., Japan) with the thermo-recorder.

\section{Results and Discussion}

The moisture balance of each reactor is shown in Table 3. It was believed that the amount of nutrients transferred to the packing layer was higher than expected because of two parameters: the amount of moisture transferred and nutrient concentration. Although the nutrient supply method was carried out by the same method (soaking), BF2 had a higher water evaporation rate than $\mathrm{BF} 1$ and $\mathrm{BF}$. It is likely that the moisture evaporation rate of $\mathrm{BF} 1$ was lower than that of $\mathrm{BF} 2$ because the water content of $\mathrm{BF} 1$ was consistently high due to frequent irrigation (twice weekly). Excess water contents tend to decrease the specific surface area of the porous materials and it may negatively affect water vaporization. Moreover, it is believed that overgrowth of microorganisms leads to higher moisture retention. This phenomenon was noteworthy in BF1. However, based on visual 
observation, the packing material of $\mathrm{BF} 3$ was sufficiently dry during the irrigation period. It is possible that the frequency of humidity measurement (once daily) was inadequate to determine the moisture balance because the evaporation to retention ratios was extremely low. More frequent humidity measurements, for example after every few hours, may be necessary.

The results of the VOCs removal experiment are summarized in Fig. 3. Almost complete removal of toluene was achieved in BF1. However, a certain amount of toluene remained in the outlets of BF2 and BF3. Drying out of the packing layer due to less frequent irrigation and uneven distribution of moisture and nutrients supplied by spraying irrigation are possible reasons for incomplete toluene removal in $\mathrm{BF} 2$ and BF3, respectively. Generally, MEK removal efficiency was higher than toluene removal efficiency. However, the relative removal trend of the three reactors was similar to the toluene removal trend.

Considering the gaseous VOCs removal and moisture evaporation, the heat generated in each reactor was estimated. The results of the heat balance calculation based on Eq. (1) are shown in Table 4.

$$
E s=E d-E m-E e
$$

where

$E s$ is the heat accumulated in the packing layer;

$E d$ is the heat produced by VOCs decomposition;

$\mathrm{Em}$ is the heat transferred from the packing layer to the air flow;

And $E e$ is the heat consumed by moisture evaporation.

Generally, negative values were obtained in this experiment. It indicates that the heat loss due to evaporation of water is more than the heat produced by VOCs decomposition. This value approached zero only before irrigation in $\mathrm{BF} 3$. In practice, the negative value of the heat balance will be larger than the values obtained in this evaluation since the energy used for microbial growth was not considered in this study.

These results suggest that the dominant driving force of water evaporation was not the heat generated by
Table 3 Moisture balance of each reactor.

\begin{tabular}{lllll}
\hline & & BF1 & BF2 & BF3 \\
\hline $\begin{array}{l}\text { Time/period } \\
\begin{array}{l}\text { Cumulative moisture } \\
\text { evaporation }\end{array}\end{array}$ & $(\mathrm{mL})$ & 1973 & 1401 & 1128 \\
$\begin{array}{l}\text { Cumulative moisture } \\
\text { retention }\end{array}$ & $(\mathrm{mL})$ & 3420 & 1640 & 1950 \\
Evaporation rate & $(\%)$ & 58 & 85 & 58 \\
\hline
\end{tabular}

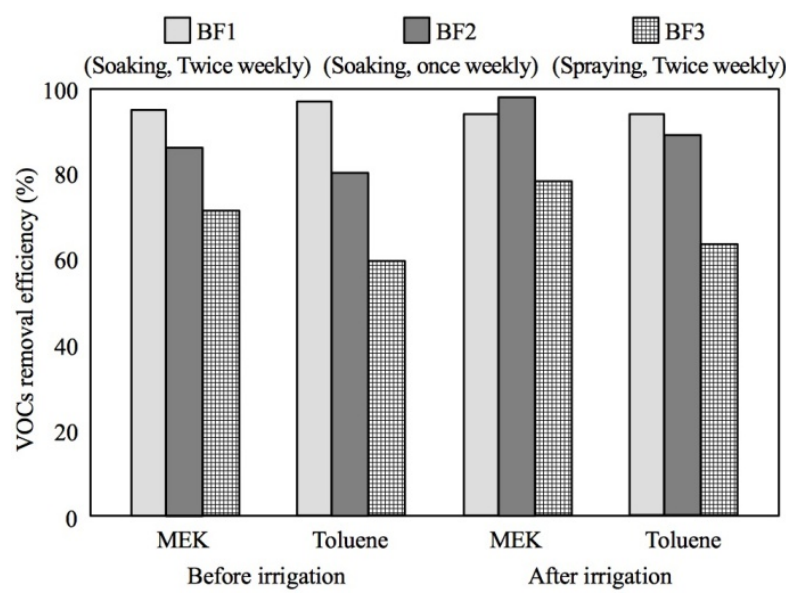

Fig. 3 Summary of the results of gaseous VOCs removal.

Table 4 Heat balance of each reactor.

\begin{tabular}{lccc}
\hline & BF1 & BF2 & BF3 \\
\hline Time/period (d) & $4-46$ & $4-46$ & $4-46$ \\
$\begin{array}{l}\text { Heat accumulated } \\
\text { before irrigation }\left(\mathrm{kJ}^{-} \mathrm{day}^{-1}\right)\end{array}$ & -44.2 & -22.7 & -4.7 \\
$\begin{array}{l}\text { Heat accumulated } \\
\text { after irrigation }\left(\mathrm{kJ} \cdot \mathrm{day}^{-1}\right)\end{array}$ & -48.2 & -25.9 & -24.6 \\
\hline
\end{tabular}

VOCs decomposition but the humidity difference between the packing layer and the gas phase. Therefore, for VOCs removal by biofiltration, under similar operating conditions, controlling the moisture content of the air is very important for controlling the moisture content of the packing layer. However, this moisture balance must be altered for reactors operated with higher inlet load of gaseous VOCs. Further experiments under different operating conditions are required to assess the influences of the moisture and heat balances on biofilter performance.

\section{Conclusion}

In this study, the moisture behavior and gas removal efficiencies of reactors with different irrigation methods (soaking or spraying) and frequency of 
irrigation were compared. Within the range of the operating conditions used in this study, the gaseous VOCs removal efficiency was highest in the reactor with frequent and soaking irrigation (BF1). This was probably because the supply of moisture and nutrients were adequate. However, the moisture evaporation rate was low and overgrowth of microorganisms was observed in the packing layer in this reactor. In the reactor with less frequent irrigation (BF2), the moisture evaporation rate increased while the VOCs removal efficiency decreased. Soaking irrigation had more advantages over spraying irrigation with respect to both gaseous VOCs removal efficiency and moisture supply. Under the conditions used in this study, the heat consumed by moisture evaporation exceeded the heat generated by VOCs decomposition. More frequent measurements of moisture are critical for establishing appropriate methods for moisture control in biofiltration.

\section{References}

[1] Devinny, J. S., Deshusses, M. A., and Webster, T. S. 1999. Biofiltration for Air Pollution Control. Boca Raton, FL: CRC Lewis Publishers.

[2] Kennes, C., Rene, E. R., and Veiga, M. C. 2009. "Bioprocesses for Air Pollution Control." Chemical Technology and Biotechnology 84 (10): 1419-36.

[3] Detchanamurthy, S., and Gostomski, P. A. 2012.
"Biofiltration for Treating VOCs: An Overview." Reviews in Environmental Science and Bio-Technology 11 (3): 231-41.

[4] Klapkova, E., Halecky, M., Fitch, M., and Soccol, C. R. 2006. "Impacts of Biocatalyst and Moisture Content on Toluene/Xylene Mixture Biofiltration." Brazilian Archives of Biology and Technology 49 (6): 1001-6.

[5] Sun, Y., Quan, X., Chen, J., Yang, F., Xue, D., Lui, Y., et al. 2002. "Toluene Vapor Degradation and Microbial Community in Biofilter at Various Moisture Content." Process Biochemistry 38 (1): 109-13.

[6] Mudilar, S., Giri, B., Padoley, K., Satpute, D., and Dixit, R. 2010. "Bioreactors for Treatment of VOCs and Odors-A Review." Journal of Environmental Management 91 (5): 1039-54.

[7] Beuger, A. L., and Gostomski, P. A. 2009. "Development of a Biofilter with Water Content Control for Research Purposes." Chemical Engineering Journal 151 (1-3): 89-96.

[8] Armeen, A., Feddes, J., Leonard, J., and Coleman R. N. 2008. "Biofilters to Treat Swine Facility Air: Part 2. Water Application Rate." Canadian Biosystems Engineering 50: 6.57-6.64.

[9] Cheng, Y., He, H., Yang, C., and Zeng, G. 2016. "Challenges and Solutions for Biofiltration of Hydrophobic Volatile Organic Compounds." Biotechnology Advances 34 (6): 1091-102.

[10] Malhautier, L., Khammar, N., and Bayl, S. 2005. "Biofiltration of Volatile Organic Compounds." Applied Microbiology and Biotechnology 68 (1): 16-22.

[11] Morita, Y., Okunishi, S., and Higuchi, T. 2012. "Optimizing Nutrient Supply in a Rotatory-Switching Biofilter for Toluene Vapor Treatment." Journal of the Air \& Waste Management Association 62 (4): 451-60. 